\title{
IFaz de conta: o teatro como ferramenta de desenvolvimento da leitura, oralidade, escrita e expressão corporal
}

\author{
Patricia de Lara Ramos \\ Docente. Instituto Federal de Educação Ciência e Tecnologia do Paraná (IFPR - Campus Cascavel) \\ (patricia.ramos@ifpr.edu.br) \\ Mauricio Marcelino de Lima \\ Docente. Instituto Federal de Educação Ciência e Tecnologia do Paraná (IFPR - Campus Cascavel) \\ (mauricio.lima@ifpr.edu.br) \\ Emily Sabrina Guedes Primenta \\ Instituto Federal de Educação Ciência e Tecnologia do Paraná (IFPR - Campus Cascavel) \\ (emilygp1@hotmail.com)
}

\begin{abstract}
Resumo: Este relato de experiência se refere a um projeto de extensão intitulado IFaz de conta, que tem sido desenvolvido no IFPR - Campus Cascavel, desde 2016, e que tem como escopo principal o desenvolvimento de habilidades de leitura, oralidade, escrita e expressão corporal com os alunos participantes por meio de práticas teatrais. Para tanto, no ano passado, foram trabalhadas peças teatrais contemporâneas curtas voltadas ao público infantil e juvenil, com o propósito de exibir espetáculos interna e externamente ao Campus Cascavel. Metodologicamente, o projeto foi desenvolvido a partir da Ludopedagogia, isto é, explorando os jogos teatrais com a finalidade de fazer com que os alunos tivessem suas habilidades orais, escritas e expressivas aprimoradas. Os resultados indicam que os discentes envolvidos no projeto tiveram um progresso significativo e perceptível de suas habilidades criativas e dinâmicas após sete meses de encontros semanais, permitindo-Ihes apresentar duas peças para o campus Cascavel, sendo que uma delas foi, também, apresentada em uma escola pública municipal. Ademais, todo esse (des)envolvimento auxiliou na promoção dos alunos em sala de aula, de modo que pudessem demonstrar maior facilidade na leitura e compreensão de textos diversos, oriundos dos mais variados componentes curriculares.
\end{abstract}

Palavras-chave: Teatro; Habilidades de leitura/orais e escritas; Ludopedagogia.

\section{IFaz de conta: theater as a tool for the development of reading, orality, writing and corporal expression}

\begin{abstract}
This experience account refers to an extension project titled IFaz de conta, that has been developed at the IFPR - Cascavel Campus since 2016, and which has as its main scope the development of reading, speaking, writing and body expression skills in students through theatrical practices. To this end, last year, contemporary short plays aimed at children and young people were organised with the purpose of performing plays internally and externally to the Cascavel Campus. Methodologically, the project was developed from the Ludopedagogy that is, exploring the theatrical games with the purpose of making students have their oral, written and expressive skills improved. The results indicate that the students involved in the project had a significant and noticeable progress of their creative and dynamic skills after seven months of weekly meetings, allowing them to perform two plays to the Cascavel Campus, and one of them was also performed in a municipal public school. Moreover, all of this development helped promoting students in the classroom, so that they could demonstrate greater ease in reading and understanding different texts from the various curricular components.
\end{abstract}

Keywords: Teather; Reading/oral and writing skills; Ludopedagogy. 


\section{INTRODUÇÃO}

O relato que ora nos propomos a fazer é oriundo de um projeto de extensão, submetido ao Instituto Federal do Paraná (IFPR), para aquisição de bolsas no Programa de Bolsas Acadêmicas de Inclusão Social (PBIS) aos alunos que se encontram em vulnerabilidade socioeconômica. Além disso, ele foi planejado a partir do desejo dos professores envolvidos de cotejar arte e literatura, envolvendo alunos de cursos, séries, idades e níveis de conhecimento distintos.

O objetivo principal desse intento foi ampliar a ação formadora social e intelectual dos discentes (leitura, oralidade, escrita e expressão corporal), aprimorando, assim, a interação social com a vida e com o mundo ao redor de cada sujeito envolvido, de modo a favorecer as relações harmônicas em sociedade, desinibindo os que têm problemas com timidez e auxiliando os que têm dificuldade de se expressar diante de situações que exigem exposição oral ou escrita.

Além disso, outros propósitos estavam atrelados ao primeiro, tais como: 1) oportunizar ao discente a busca por um conhecimento sistêmico, envolvendo as mais variadas situações e lugares (cultura e espaço cultural, realidade, política, meio social e habilidades artísticas); 2) romper a estagnação cultural que paira sobre a sociedade; 3) estimular a produção teatral e as habilidades a ela relacionadas - a concentração, a leitura, a expressão oral e escrita (produção de textos) dos alunos; 4) possibilitar a reflexão sobre a arte e o conhecimento técnico sobre o teatro: história, técnicas de respiração, impostação vocal e postura cênica; 5) trabalhar com diferentes linguagens teatrais, envolvendo a música, as coreografias e as artes plásticas para construir as personagens, o figurino e o cenário.

À luz dessas intenções, é meritório destacar que, de acordo com levantamento feito, o teatro na escola vem apresentando uma importância fundamental no desenvolvimento educacional, já que permite fazer com que o aluno aprimore habilidades como a socialização, a integração, a criatividade, a coordenação, a memorização, o vocabulário, entre outros, a partir dos encontros/oficinas teatrais.

Por meio do teatro, o professor consegue perceber traços da personalidade do aluno, de que maneira se comporta individual e grupalmente e, a partir disso, estabelecer um plano de trabalho que tenha maior eficácia para cada sujeito envolvido no projeto. Além disso, o teatro é um exercício de cidadania, que ajuda a 
ampliar significativamente o repertório cultural e a compreensão dos mais distintos temas:

\begin{abstract}
O teatro ajuda na abordagem de temas polêmicos, como drogas, sexo, racismo, discriminação, prostituição, doenças sexualmente transmissíveis, entre outros. É um instrumento facilitador do diálogo entre alunos e professores criando um ambiente aberto, sem o estigma da sala de aula, aberta e dispersa. Existe um comprometimento maior por parte dos integrantes do grupo, pois o aluno deixa de ser coadjuvante e atinge o status de protagonista, pois ele tem voz e é ouvido, tem ideias, e essas são aceitas. A criatividade aflora deixando os sentidos mais alertas e receptivos a aprendizagem. (DAVÖ, 2015, p. 66)
\end{abstract}

Salientamos, ainda, que a Lei de Diretrizes e bases da Educação (LDB), reformulada em 2016, apresenta o ensino da arte como obrigatório na educação básica:

Art.26 $\S 2^{\circ}$ O ensino da arte, especialmente em suas expressões regionais, constituirá componente curricular obrigatório da educação básica.

$\S 60$ As artes visuais, a dança, a música e o teatro são as linguagens que constituirão o componente curricular de que trata $0 \S 2^{\circ}$ deste artigo. (LDB 9.394/96)

Com base nos PCNs - Ensino Médio (2000), o teatro é uma ferramenta capaz de auxiliar na formação identitária do jovem, além de possibilitar articulações com as demais linguagens da área de Linguagem, Códigos e suas Tecnologias:

Os estudantes que frequentam a escola média, ao desenvolverem saberes artísticos por meio das linguagens e códigos da música, artes visuais, dança, teatro, artes audiovisuais, podem aprender a desvelar uma pluralidade de significados, de interferências culturais, econômicas, políticas atuantes nessas manifestações culturais. Aos poucos, os alunos, através de pesquisas, observações, análises, críticas, podem descobrir como vão sendo tecidas e transformadas as histórias:

- Dos produtores de arte ou artistas;

- Dos seus produtos ou obras de arte;

- Dos difusores comunicacionais da produção artísticas;

- Dos públicos apreciadores de arte no âmbito da multiculturalidade.

(BRASIL, 2000, p. 49-50).

Assim, em meio às variadas manifestações da arte, o teatro pode ser considerado uma ferramenta capaz de alimentar o intelecto humano e propiciar 
leituras plurais do mundo ao qual pertencemos, que foge do aparente e entra no simbólico, na ideia que a arte pode transmitir: "é o invisível-intuído, tornado visível através de imagens simbólicas, de sensações físicas e emoções" (AMARAL, 1996, p. 26), e quando fazemos isso na escola, incontáveis habilidades são desenvolvidas, dentre elas, em nosso ponto de vista, são a leitura, a oralidade, a escrita e a expressão corporal. Contudo, não somente essas habilidades são importantes, mas aquelas atreladas ao emocional (já que as peças teatrais falam ao nosso consciente e ao nosso inconsciente), que levam à compreensão de temas que pairam sobre a sociedade e ensinam os mais variados assuntos, extirpando conceitos antigos e moldando novos mediante à experimentação, ao fazer de conta.

Dessa forma, podemos dizer que o teatro é uma viagem imaginária (encarregada de transmitir conhecimentos, emoções, prazeres e provocar análises e questionamentos) propiciada pelo envolvimento dos artistas (por meio da oralidade e da expressão corporal), da produção (cenário, sonoplastia, figurino, maquiagem) e do público (aquele que participa, envolve-se, permite que os artistas se desnudem e assumam outras personas para transmitir uma mensagem).

Um ato teatral acontece quando o indivíduo que o executa se modifica, ou na medida em que coloca outra personalidade em lugar da própria, e suas atitudes não são mais habituais. É outro o seu tom de voz, é outra a sua aparência, trata e representa outra coisa que não a sua simples rotina. É o personagem. É quando o homem simplesmente deixa de ser o que é, para aparentar ou simbolizar algo além de si próprio e passa a revelar uma outra realidade. (AMARAL, 1996, p. 26)

O teatro é um mecanismo capaz de desencarcerar o homem de uma condição cultural linear, fazendo-o se aventurar em uma condição mais profunda, complexa, inovadora e excitante. Isso porque os pensamentos, o modo de enxergar as coisas, a percepção e a cognição são amplamente estendidas, e, desse modo, o homem é capaz de responder melhor aos seus anseios cotidianos dos loci onde está inserido. Em outras palavras, o teatro é responsável por levar o homem a descobrir quem ele realmente é, o que sente e o que deseja para si, é o espelho que reflete e refrata o mundo. Talvez, muitos se perguntem: por que o teatro? Por que não outra manifestação artística? E Augusto Boal nos responde:

Porque existem artes, como a música, que organizam o som e o silêncio, no tempo; outras, como a pintura, que organizam a forma e 
a cor, no espaço; e existem artes como o teatro, que organizam ações humanas, no espaço e no tempo.

Ao organizarem ações humanas, mostram onde se esteve, onde se está e para onde se vai: quem somos, o que sentimos e o que desejamos. Por isso, devemos fazer teatro, todos nós: para saber quem somos e descobrir quem podemos vir a ser. (BOAL, 2003, p. 90)

Por fim, vale ressaltar que o contato com a linguagem teatral auxilia os adolescentes a perderem a timidez, justamente por assumirem o papel do outro; a desenvolverem e priorizarem a noção do trabalho em grupo, uma vez que o teatro não se faz sozinho, por mais solitário que se esteja no palco; a terem sucesso em situações que exigem o improviso, especialmente oral, diante dos infindos acontecimentos hodiernos, e a se interessarem mais por textos e autores variados, aprimorando, consequentemente, o ato da escrita. Logo, para nós, professores das áreas de Letras e Artes, o teatro seria a prática que nos ajudaria a estimular e desenvolver os alunos interessados, bem como auxiliaria a promover reflexão no público (que seria, em sua maioria, os próprios alunos da instituição).

\section{METODOLOGIA TEATRAL: A LUDOPEDAGOGIA A PARTIR DE JOGOS TEATRAIS}

A iniciação ao teatro nem sempre acontece na educação infantil ou nos primeiros anos do ensino fundamental, pode, em alguns casos, ser iniciada no segundo ciclo do ensino fundamental e, até mesmo, no nível médio. Em várias instituições de ensino, como em colégios e institutos federais, onde há o incentivo a projetos de extensão, a linguagem teatral encontra espaços específicos e, também, mais sólidos, além das aulas regulares de arte. Nesse ínterim, o teatro surge com o intuito de promover de modo mais qualitativo o desenvolvimento de habilidades de comunicação e expressão, seja para alunos que apresentem afinidade com essas habilidades, seja para aqueles que têm dificuldades.

À vista disso, o projeto IFaz de Conta trabalhou com alunos na faixa etária dos 14 (catorze) aos 17 (dezessete) anos, originários de cursos técnicos integrados ao ensino médio, sendo que alguns não tiveram acesso a práticas teatrais e aos conteúdos que envolvem o teatro em níveis anteriores de sua escolarização. Isso se 
deve à recente obrigatoriedade do ensino específico do teatro na educação básica, sendo incluída como componente obrigatório dentro da disciplina de artes, como vimos, apenas em 2016, pela Lei de Diretrizes e Bases da Educação (BRASIL, 1996).

Ao longo de nossa prática, observamos que antes da atualização da legislação, o ensino na disciplina de artes era amplificado e desenvolvido a partir da formação do professor, que poderia ser nas variadas linguagens da arte, como a música, a dança e as artes visuais. Desse modo, a seleção dos conteúdos que integrariam o currículo nos diferentes estados e municípios ficava, então, a cargo dos sistemas de ensino e dos arte-educadores, que acabavam, muitas vezes, deixando o teatro de lado, por falta de conhecimento, leitura e proximidade com as artes cênicas. Essa brecha na legislação, que só foi recentemente corrigida, acabou causando, em alguns casos, uma deficiência de conteúdos e a ausência na promoção de habilidades que são comumente desenvolvidas por meio do teatro. Ademais, a recente alteração legal, tornou o ensino do teatro um desafio presente nas instituições de formação básica, pois embora ele deva acontecer, muitas vezes, não há estrutura, recursos necessários e carga horária suficiente para o desdobramento das atividades teatrais.

Diante dessas fragilidades, os docentes precisam estar munidos de metodologias diversificadas, partindo de ações práticas que envolvam temas inerentes ao cotidiano dos alunos e que não necessitem de um arcabouço artístico tão elaborado, visto que não possuímos recursos para a aquisição, nem mesmo espaço para o armazenamento de ferramentas artísticas ${ }^{1}$. A estratégia utilizada é o envolvimento do lúdico, que trabalha com a descontração, com o humor e com a interação coletiva por intermédio da brincadeira. Um exemplo disso são os jogos teatrais e a improvisação, ambos dirigidos com regras bem definidas e que promovem resultados visíveis no desenvolvimento de competências expressivas.

A utilização do lúdico não é uma prática particular ao desenvolvimento teatral, envolve várias áreas da aprendizagem, especialmente na formação inicial do aluno, nos primeiros anos de escolarização. Segundo Vygotsky, "A criação de uma situação imaginária não é algo fortuito na vida da criança; pelo contrário, é a primeira

\footnotetext{
1 Consideramos, neste trabalho, os termos "arcabouço artístico" e "ferramentas artísticas" como sendo todos os recursos artísticos necessários para compor uma atividade inerente à arte, tais como desenhar, pintar, esculpir, fotografar, colar, modelar, recitar, escrever, representar, cantar, dançar, entre outros.
} 
manifestação da emancipação da criança em relação às restrições situacionais". (VYGOTSKY, 1998, p. 130).

Nesse sentido, percebe-se que o desenvolvimento da imaginação é um elemento essencial para a emancipação do indivíduo desde a infância, passando pela adolescência até o alcance da fase adulta. O lúdico, ou seja, a brincadeira, torna-se uma atividade decisiva para o aprimoramento do pensamento imaginativo e abstrato do indivíduo: "o brincar prepara para futuras atividades de trabalho: evoca atenção e concentração, estimula a autoestima e ajuda a desenvolver relações de confiança consigo e com os outros" (ROLIM et al, 2008, p. 176).

O teatro é uma atividade que exige do aluno essas potencialidades destacadas pela autora: a atenção, a concentração e as relações coletivas, somando-se, ainda, com a questão da imaginação, salientada por Vygotsky (1998). Isso significa dizer que quando os alunos da educação infantil não têm essas habilidades bem trabalhadas e não há, durante a vida escolar, o estímulo para aperfeiçoá-las, eles podem chegar à adolescência com dificuldades de lidar com situações cotidianas, especialmente, a comunicação e expressividade, como por exemplo, em uma simples apresentação de trabalho em sala de aula. É por isso que o estudo da arte, e, neste caso, especialmente, o da linguagem teatral, configura-se como componente curricular importante na formação humana.

Segundo Cartaxo, o teatro se apresenta como uma ferramenta que não pode ser suprimida nos processos de ensino-aprendizagem, pois “... desperta, provoca, sensibiliza e educa a quem vivencia e a quem assiste, possibilitando assim, a formação de um homem novo, capaz de contribuir na construção de uma sociedade justa, fraterna e igualitária" (2001, p.37).

Contudo, em algumas realidades, essa linguagem pode ter sido trabalhada superficialmente, não atendendo às necessidades de desenvolvimento humano e social que os indivíduos necessitam para contribuírem na formação dessa sociedade (justa, fraterna e igualitária) salientada pelo teórico. Isso acontece por conta da ausência das habilidades que só podem ser plenamente apreendidas através da linguagem do teatro, contribuindo com a sensibilização, com a comunicação e a interpretação do outro e a de sí mesmo, respeitando e compreendendo como lidar no individual e coletivamente, em diferentes modos de expressão, criação e comportamento. 
Teatro - ou teatralidade - é aquela capacidade ou propriedade humana que permite que o sujeito se observe a si mesmo, em ação, em atividade. $\mathrm{O}$ autoconhecimento assim adquirido permite-Ihe ser sujeito (aquele que observa) de um outro sujeito (aquele que age); permite-lhe imaginar variantes ao seu agir, estudar alternativas. $O$ ser humano pode ver-se no ato de ver, de agir, de sentir, de pensar. Ele pode se sentir sentindo, e se pensar pensando (BOAL, 1996, p. 27).

Quando não existe a compreensão sensível do coletivo, e do seu próprio lugar na sociedade podem surgir indivíduos egoístas, incompreensíveis, vulneráveis a comportamentos hostis e que se afastam da vida comunitária saudável e respeitosa, pois o diferente pode se tornar intolerável para ele.

Como pauta Boal (1996), o autoconhecimento, adquirido por intermédio do teatro, permite a ação e interação de si com o outro, de se fazer compreendido e de compreender, podendo ser notado, mas, principalmente, conseguindo notar o próximo. Ele ajuda-nos a esclarecer que fazemos parte de um lugar que não é apenas singular, mas sim coletivo, e que há diversos modos de agir, pensar e de ser compreendido, compreendendo, sentindo e aceitando os que são diferentes de si.

$\mathrm{Na}$ tentativa de sanar possíveis defasagens de tais habilidades e aperfeiçoálas, o projeto IFaz de conta fez o uso da Ludopedagogia para a inicialização das práticas teatrais, visando o estímulo do imaginário, da comunicação corporal e oral, bem como da criatividade, leitura e escrita.

\footnotetext{
A concepção predominante em teatro-educação vê a criança como um organismo em desenvolvimento, cujas potencialidades se realizam desde que seja permitido a ela desenvolver-se em um ambiente aberto à experiência. $O$ objetivo é a livre expressão da imaginação criativa (KOUDELA, 2012, p. 18).
}

Embora a autora enfatize a importância do teatro no desenvolvimento da experiência e da imaginação criativa na criança, o adolescente, alvo do projeto supracitado, também se encontra em uma fase de desenvolvimento, e a retomada de habilidades que permitem a imaginação, a experiência com seu meio coletivo e a criatividade, são elementos cruciais para que ele se familiarize com o teatro. Decerto, para o sucesso do projeto, a retomada dessas potencialidades tornou-se indispensável, utilizando-se da brincadeira, a partir da metodologia dos jogos teatrais e da improvisação, como recurso de iniciação à dramatização. 
Essas técnicas estão atreladas ao conceito de ludicidade, ou, como é conhecido na pedagogia, de ludopedagogia. Essa pedagogia se baseia no ensino a partir de atividades lúdicas, com o intuito de otimizar o ensino do estudante. Nessa senda, Luckesi destaca:

Uma educação que leve em consideração a ludicidade e um fazer humano mais amplo, que se relaciona não apenas à presença das brincadeiras ou jogos, mas também a um sentimento, atitude do sujeito envolvido na ação, que se refere a um prazer de celebração em função do envolvimento genuíno com a atividade, a sensação de plenitude que acompanha as coisas significativas e verdadeiras. (LUCKESI, 2000, p. 57)

$\mathrm{Na}$ fase de iniciação do nosso trabalho com o teatro, as atividades tiveram como objetivo criar um ambiente cênico mais descontraído e confortável para o aluno, buscando, assim, transformar o ato cênico em uma brincadeira, em um jogo, quebrando toda a formalidade do teatro tradicional, que exige do ator maestria e responsabilidade em sua atuação. Essa escolha se deve ao fato da necessidade de romper com a insegurança e com a ansiedade, fatores que podem moderar a qualidade da encenação, essencialmente, quando o ator (iniciante) possui dificuldade de encenar perante a pressão involuntária causada pelo público, que se encontra na plateia.

O ator, seja profissional, seja amador, no dia de seu estrelato, não tem espaço para ensaios e retificações, ele é exposto, de modo direto, ao público e deve estar preparado. Desse modo, o desenvolvimento de técnicas a partir de atividades que reafirmem as habilidades de concentração, expressão e comunicação corporal/vocal devem ser amplamente trabalhadas. O jogo, nesse processo, torna a ação do ator prazerosa, traz a alegria, permite a improvisação e o erro, possibilita o amadurecimento da atuação dramática, ou, conforme argumenta Luckesi (2000), torna a ação uma celebração, passando a ideia de plenitude.

Nas palavras de Friedmann, "o lúdico faz parte do patrimônio lúdico-cultural, traduzindo valores, costumes, formas de pensamento e ensinamento" (FRIEDMANN, 1996, p. 30). Nesse sentido, o teatro e a ludicidade se interceptam, pois o teatro, assim como o lúdico, também comunica e representa a produção cultural, o pensamento, os costumes e valores, como salientou Peixoto, "o Teatro tem uma 
história específica, capítulo essencial da história da produção cultural da humanidade" (PEIXOTO, 2012, p. 11).

A proximidade do teatro com o cotidiano do indivíduo, seu viés recreativo, dinâmico, imaginativo e coletivo, assim como o da brincadeira, torna o uso do lúdico, a partir do método da ludopedagogia, um instrumento relevante e coerente com as novas formas de ensino da linguagem teatral, especialmente após a superação da pedagogia tradicional, no século $\mathrm{XX}$ :

O ensino do teatro na escola foi revolucionado a partir do movimento da Escola Nova. Ele não se refere a só um tipo de escola ou sistema didático determinado, mas a todo um conjunto de princípios tendentes a rever as formas tradicionais de ensino. No século XIX, o educador preocupava-se mais com os fins da educação do que 0 processo de aprendizagem (KOUDELA, 2012, p. 18).

A partir dessa ampliação de concepção no processo de ensino-aprendizagem, a incrementação e 0 uso de novas metodologias que oportunizassem 0 desenvolvimento do aluno, o teatro tornou-se um campo de estudo mais aberto e preocupado em resolver as lacunas apresentadas nos processos de ensinoaprendizagem tradicionais, priorizando, assim, o estímulo e aperfeiçoamento das habilidades, não apenas o produto final, como ressalta Koudela (2012).

A diversificação das metodologias possibilitou, no teatro, que os alunos que não apresentassem pré-disposição e interesse pela atuação dramática pudessem ser estimulados para superar suas dificuldades de expressividade e comunicação. Tais metodologias são diferentes da pedagogia tradicional, que nem sempre se preocupava em trabalhar de maneira inovadora, o que, indiretamente, poderia priorizar os alunos que já apresentavam as habilidades básicas do teatro. Isso poderia levar o aluno que não teve as potencialidades de expressão e interação coletivas desenvolvidas ao desânimo.

De acordo com a pesquisadora Mariana Tagliari "o Lúdico é utilizado para provocar o riso e ao mesmo tempo apresentar alguns aspectos teatrais, como personagens, relação entre os atores e o texto cênico" (2015, p. 94). Decerto, a possibilidade de tornar a iniciação ao teatro algo prazeroso, a partir de atividades lúdicas, podendo conquistar até os mais inibidos, faz do jogo/brincadeira uma alternativa metodológica significativa. Ela se torna uma possibilidade estimulante no 
ensino do teatro, especialmente por introduzir de maneira diversificada os conceitos essenciais dessa linguagem, como bem destacou a autora.

Koudela, baseada em Slade, enfatiza que "o valor máximo da atividade", ou seja, do jogo teatral "é a espontaneidade a ser atingida através da absorção e sinceridade durante a realização do jogo" (KOUDELA, 2012, p. 22). É nessa perspectiva que o jogo se apresenta como uma metodologia lúdica, priorizando o espontâneo e a brincadeira. Afinal, quando a criança e o jovem brincam, seja com um brinquedo, seja em um jogo com regras norteadoras, tornam-se capazes de se expressar de modo mais criativo e genuíno.

Tais características são importantes no desenvolvimento da atuação dramática e na desinibição do indivíduo, especialmente dos que não estão familiarizados com ela. O sucesso na interpretação cênica está justamente na naturalidade em que o ator representa seu personagem. É a partir dessa lógica que a ludopedagogia pode contribuir na projeção do aluno para o seu aperfeiçoamento na performance teatral e também em suas práticas cotidianas.

No projeto IFaz de Conta, essa metodologia, baseada no lúdico, tornou-se a principal alternativa para trabalhar a desinibição dos alunos que apresentavam dificuldade de expressão. Estes, quando estimulados a dramatizar algum personagem, antes de terem contato com atividades e jogos lúdicos, nem sempre conseguiam se expressar de maneira clara e satisfatória, talvez pela pressão que é estar atuando diante dos colegas, do professor e até mesmo do público.

Contudo, é importante destacar que após a utilização dos jogos dramáticos e de improvisação, percebeu-se que o lúdico, por permitir o riso e a espontaneidade individual, como destacou Koudela (2012), facilitou a familiarização com a linguagem teatral. Isso também contribuiu no amadurecimento das performances dramáticas e nas relações coletivas entre os demais participantes da cena, surtindo, posteriormente, um efeito positivo nas apresentações teatrais ocorridas no desenrolar do projeto.

Para entender melhor como o jogo teatral é pensado e aplicado pelos profissionais da área do teatro, Koudela, a partir da leitura e análise da pesquisadora Viola Spolin, explicita o funcionamento da metodologia: 
a espontaneidade, a ser atingida através da absorção e sinceridade durante a realização do jogo. Dentre os muitos valores do drama está o valor emocional, e Slade propõe que o jogo dramático forneça [...] "uma válvula de escape, uma catarse emocional" (KOUDELA, 2012, p. 22).

Explicitado o objetivo e a forma como o jogo teatral é pensado, como atividade que desenvolve a dramaticidade, é possível compreender que o estímulo às experimentações emocionais individuais se caracteriza como uma estratégia para que os indivíduos possam exprimir seus sentimentos reprimidos e suas fragilidades emocionais. É só assim, a partir da resolução de suas próprias dificuldades de expressão sentimental, que ele será capaz de representar o papel que the será atribuído, interagindo com os demais personagens, inicialmente, no jogo e, posteriormente, nas montagens das peças.

[...] o jogo teatral não deve ser visto apenas do ponto de vista lúdico, sem o viés da criticidade, tampouco deve ser utilizado como metodologia sem nenhum fim, apenas para preencher aulas [...] $\mathrm{O}$ jogo teatral possibilita ao aluno estar em contato com os outros integrantes, para juntos alcançar algum objetivo e um conhecimento teatral. A experiência torna-se o ponto-chave desse aprendizado, que se baseia nas relações múltiplas que o jogador pode vivenciar durante 0 jogo teatral, tendo como experiência central, nessa intervenção, a relação espaço-corpo-indivíduo crítico (TAGLIARI, 2015, p. 127).

O destaque da autora, referente à utilização do lúdico, nos jogos teatrais, como uma metodologia que apresenta objetivos críticos, é um aspecto importante para que o aluno possa aproveitar de maneira efetiva suas potencialidades expressivas, seja na ação dramática, seja na vida cotidiana.

O envolvimento crítico dos alunos no jogo torna-se primordial para que eles consigam aprender os elementos básicos de relação presentes no teatro - o espaço o corpo e o indivíduo -, bem como o desenvolvimento de suas faculdades intelectuais para a formação humana. Afinal, o público do projeto aqui relatado é de jovens em situações de vulnerabilidade socioeconômica, e a intenção desse não é a formação do ator profissional, embora ele possa escolher este caminho se for de seu interesse, mas o desenvolvimento de relações interpessoais e de habilidades que possam contribuir na sua formação universal. 
Outro aspecto relevante na utilização do jogo teatral, destacado por Koudela, é que "por intermédio do envolvimento criado pela relação de jogo, o participante desenvolve liberdade pessoal dentro de limite de regras estabelecidas" (2012, p. 43). Essa liberdade criada pelo participante só é estabelecida devido à forma lúdica como a atividade é trabalhada, deixando o aluno confortável para a elaboração de sua espontaneidade.

O jogo teatral, ao estabelecer um conjunto de regras ao jogador e por se tratar de uma atividade lúdica, faz isso de maneira diferente da vida real, proporcionando o desenvolvimento da segurança pessoal a partir da liberdade, pois, na brincadeira, o erro é visto de maneira menos radical, possibilitando a reprise, distinguindo-se das pressões e responsabilidades da realidade, que, na maioria das vezes, não permite a retificação. Ademais, ele também trabalha a questão da disciplina, característica tão cara na sociedade atual, contribuindo nas relações interpessoais e institucionais. Tais atributos expandem-se para além da formação artística, contribuindo essencialmente para a formação social, cultural e coletiva.

De maneira ampla, a ludopedagogia, desenvolvida a partir dos jogos teatrais, enfatiza a brincadeira para amenizar as pressões e dificuldades que assolam a expressão dramática no âmbito da coletividade. Caracteriza-se como uma metodologia de inicialização ao teatro, especialmente, a do projeto aqui apresentado. Tal método, seguindo os ideais progressistas das novas formas de conceber o processo de ensino-aprendizagem, busca cativar e incluir os mais diversos alunos, sejam os que apresentam dificuldades na comunicação e expressão corporal e oral, sejam os que apresentam ampla facilidade em atuar em público.

Além disso, a expectativa do projeto não se limita ao uso do teatro como algo instrumental com o objetivo único de transformar o aluno em ator, mas de associar as habilidades desenvolvidas pelo teatro a sua vida cotidiana.

Ao tratarmos de ludicidade, pontuamos a necessidade de ela possuir um caráter de aprendizado crítico e essencial, como forma de humanização, ou seja, como um processo lúdico que não seja apenas instrumental, mas pautado nas relações sociais e no aprendizado crítico do aluno [...] (TAGLIARI, 2015, p. 159).

Assim como defende a autora, ressaltamos que o objetivo principal do projeto IFaz de Conta, quando se utiliza da metodologia dos jogos teatrais, é tentar 
despertar o senso crítico e criativo do adolescente que se encontra na fase de desenvolvimento escolar e humano. O Instituto Federal do Paraná, onde é desenvolvido o mesmo, além de se preocupar com a formação acadêmica e humana, também se preocupa com a formação profissional. Contudo, o projeto não ambiciona a imposição do teatro como o único caminho profissional a seguir, vai muito além disso, disseminando a expressividade, a criatividade e a arte como formas de visualizar e compreender o mundo a sua volta, levando-o a lidar com as adversidades por meio de uma formação cultural, social e humana.

\section{RELATANDO OS PASSOS DO PROJETO IFAZ DE CONTA: PROPOSIÇÃO, SELEÇÃO E DESENVOLVIMENTO}

Antes da proposição do projeto de extensão IFaz de conta, vários fatores foram levados em consideração, dentre eles, o espaço, que em nosso campus é restrito, uma vez que temos apenas um bloco administrativo (onde a maioria das aulas ocorre) e outro pequeno bloco didático (usado para laboratórios) e, dessa forma, precisamos respeitar todo o cronograma da instituição, bem como os colegas de trabalho, pois é sabido que é praticamente impossível eliminar o ruído/os sons em práticas teatrais, já que exigem trabalho com técnica vocal e movimento. À vista disso, não haveria um espaço apropriado para que os alunos pudessem desenvolver suas práticas. Todavia, esse fator não nos desestimulou, pelo contrário, se o nosso desafio era romper barreiras, esta seria uma ou a primeira delas.

Outro item que nos preocupou inicialmente foi a falta de recursos para a criação de figurinos, compra de maquiagem e aquisição de elementos cenográficos, que, embora o teatro minimalista seja mais leve e não exija um ambiente cenográfico elaborado, existem itens importantes e necessários para o desenrolar do fazer artístico, tudo isso atrelado à falta de espaço. Entretanto, o desejo dos professores de levar a arte, por meio do teatro, aos alunos era muito mais intenso e estávamos dispostos a enfrentar esse desafio independente dos obstáculos que tivéssemos que superar.

Após esse levantamento das impossibilidades, decidimos submeter o projeto para apreciação da Reitoria do IFPR e aguardar os resultados e o número de bolsas que nos seriam concedidas. De início, precisávamos de 11 (onze) participantes, mas 
sabíamos que, com o contingenciamento de gastos, se nosso projeto fosse selecionado, não conseguiríamos o número almejado. De fato, tivemos o aceite e o edital de PBIS n.ํ 036/2016 nos contemplou com 04 (quatro) estudantes bolsistas, porém, como a peça infantil previamente escolhida para apresentação exigia 11 (onze) personagens, decidimos publicar uma chamada interna para teste de elenco/audição para não bolsistas, com o objetivo de conseguir outros 07 (sete) alunos voluntários.

Referida chamada interna se deu pela publicação e divulgação de um edital com requisitos estabelecidos pelos professores proponentes. Findado o prazo das inscrições, por meio de formulário online no Google docs, tivemos 13 (treze) interessados para o teste de elenco, sendo que desses, 12 (doze) alunos comparecerem e 07 (sete) deles foram selecionados pela banca composta pelos professores responsáveis pelo projeto (Mauricio Marcelino de Lima e Patricia de Lara Ramos) e por um servidor técnico em assuntos educacionais (Jorge Luiz de Mendonça Ortellado Alderete). A seleção se deu a partir da avaliação dos seguintes quesitos: desenvoltura; dicção; dramatização; capacidade de improviso; expressão corporal; empatia com o público e criatividade.

De modo geral, os alunos se preparam muito bem para o teste e a banca teve uma tarefa difícil na escolha, porém, como cada membro atribuía uma pontuação para os quesitos avaliados, não haveria o que se discutir, as sete pontuações maiores ao final do teste, em ordem decrescente, seriam as escolhidas para o projeto. Feita a divulgação na instituição, os alunos bolsistas e os não bolsistas selecionados foram convocados para a primeira reunião.

Os encontros ocorriam todas as sextas-feiras à tarde, e o primeiro deles foi para orientar os alunos acerca do funcionamento do projeto, além de iniciar com discussões teóricas sobre o teatro. As quatro primeiras semanas foram voltadas à teoria, isto é, estudamos sobre voz, palco, cenário, figurino, maquiagem, personagens, improviso, entre outros temas. Na sequência, sempre fazíamos uma ou duas práticas de jogos teatrais.

As primeiras vezes foram mais difíceis, os alunos demoravam para se soltar, não conseguiam desenvolver o jogo de forma dinâmica, alguns tinham mais facilidade que outros, porém, de modo geral, a desenvoltura nos jogos teatrais foi sendo melhorada ao longo do tempo, tanto que, muitas vezes, quando os 
professores chegavam para a orientação, os alunos já estavam promovendo seus jogos teatrais favoritos (os que trabalham a voz).

Dentre os jogos aplicados, podemos destacar cinco deles:

1- Expressão vocal - exercício que trabalha com o tom de voz (alto, baixo, grave, agudo) e o desenrolar da língua (rápido, lento), por meio de travalínguas ou de outras frases solicitadas pelos orientadores;

2- Estátua: exercícios em que os alunos se mexem (dançam) ao som de uma música e ao sinal do orientador devem parar expressando o sentimento exigido (alegria, tristeza, ódio, pena...);

3- Espelho: exercício desenvolvido em duplas, no qual um aluno deve imitar o outro (sendo espelho dele);

4- Caixa de presentes: exercício em que os alunos recebem uma caixa e devem descrevê-la, com o maior número de detalhes possíveis, para que os demais consigam adivinhar o que está sendo descrito;

5- Relaxamento: técnica que exige que os alunos se sentem ou deitem confortavelmente, numa sala com iluminação restrita, com um som ambiente, e executem as instruções do orientador, tais como: imaginar um local diferente de onde estejam, alongar pernas e braços, espreguiçar-se, entre outros;

De todos os alunos selecionados para a peça infantil principal, previamente planejada para ser apresentada em dezembro de 2016, 03 (três) deles deveriam ser escolhidos para ensaiar uma peça curta, disponível na Internet, As inventariantes, de Walter Piva, a qual seria apresentada em um evento anual que temos na instituição, primeiramente, a nível local (Pré Seminário de Extensão, Ensino, Pesquisa e Inovação - Pré-Sepin), posteriormente, estadual (Seminário de Extensão, Ensino, Pesquisa e Inovação - Sepin).

De forma democrática, conversamos com o grupo, identificamos quem teria vontade de participar dessa peça e, juntos, após estudarmos o perfil das personagens, escolhemos os três atores - Emily Sabrina Guedes Pimenta (como Bárbara, mãe de Sofia e esposa de Juliano); André Zanardi de Oliveira (como Juliano, velho doente que fica na mira da filha e da esposa em um jogo de roleta russa); Thabata Laurifer (como filha do casal e proponente do jogo).

A peça foi ensaiada, porém, ao longo dos ensaios, os próprios alunos sentiram a necessidade de fazer uma adaptação, promover uma reflexão mais 
profunda ao final dela, que, inicialmente, explorava apenas a questão do tempo que a mãe e a filha despendiam para cuidar do pai, doente. Pediram-nos para escrever um final em que pudessem refletir sobre o papel da mulher na sociedade e sobre a liberdade que cada um tem de poder escolher qual rumo tomar. Autorizamos e o texto foi adaptado de uma forma bem pensada.

Também, ao longo dos ensaios, os demais alunos participantes do projeto ajudaram a planejar o cenário e a organizar a sonoplastia (sons de tiros), além disso, tínhamos um desafio: o da maquiagem, considerando que ninguém possuía habilidades para tal, bem como não tínhamos recursos para adquirir o material. Nos unimos, compramos o que precisava, quem não podia contribuir com um valor em dinheiro, trouxe o que possuía em casa, decidimos assistir aos tutoriais para aprender técnicas de envelhecimento, tentamos algumas vezes, até que, um dia, acertamos e seguimos. A apresentação ocorreu e está disponível para ser assistida em https://www.youtube.com/watch?v=BoOmY6F5uho.

Enquanto As inventariantes era ensaiada, paralelamente, a peça infantil idealizada na escrita inicial do projeto de extensão também estava em fase de estudos, já que exigia mais tempo, mais personagens, cenário, figurino e maquiagem mais elaborados. Foram muitas horas dedicadas à peça Ratimbum Pararatimbum, de Paulo Scaldassy, pois, primeiramente, os alunos quiseram adaptá-la, de modo a torná-la mais atual, substituindo canções e vocábulos antigos. Além dessa alteração, incluímos uma personagem, tarefa que exigiu a dedicação de todos para que o texto ficasse coerente.

$\mathrm{Na}$ sequência, após muito estudo, iniciamos os ensaios, que demoravam muito até que a cena ficasse exatamente como os orientadores acreditavam ser ideal. Dificilmente avançávamos e decidimos fracionar a peça em três para evoluirmos. Semanalmente, mês a mês, iniciávamos os encontros com os jogos teatrais, para aquecer os participantes, e, em seguida, partíamos para os ensaios.

A falta de recursos para a construção do cenário e confecção das roupas novamente foi um empecilho, contudo, com a autorização da Direção de Ensino, promovemos uma ação entre amigos para que conseguíssemos obter parte do dinheiro necessário para o sucesso do projeto. Com a ajuda de todos os discentes envolvidos e o resultado da ação entre amigos, pudemos criar um cenário simples e providenciar o figurino de todos os personagens. 
O espetáculo, que narra a história de um reino mágico, onde Julinho e Clarinha, duas crianças, tentam ajudar a boneca e o soldadinho de chumbo a salvarem o palhaço das garras da TV Papão, que hipnotiza as crianças com seus programas infantis e as afasta das brincadeiras e da alegria, foi apresentado na Escola Municipal Professora Arminda Tereza Villvvock, situada em Cascavel - PR, em dezembro de 2016, assim como no próprio campus, na semana de encerramento do ano letivo. O resultado das apresentações pode ser verificado em https://www.youtube.com/watch?v=MCwBuoLqPNU\&t=58s https://www.youtube.com/watch?v=0w6Jgng9x9k\&t=302s.

Os resultados do projeto são visíveis, pois os alunos bolsistas tiveram um desenvolvimento significativo, especialmente na oralidade (já que eram bastante tímidos) e na expressão corporal. Além deles, os alunos não bolsistas, que entraram no projeto porque queriam trabalhar com a arte, também cresceram e apresentaram muitas habilidades, mas a mais impressionante delas foi a escrita, a partir das adaptações dos textos teatrais.

Também, o projeto se tornou uma referência para os alunos que apreciam a área de Linguística, Letras e Artes, pois, atualmente, o campus conta com os cursos técnicos de informática e de análises químicas integrados ao ensino médio, os quais possuem uma carga horária restrita para as disciplinas de Língua Portuguesa, Literatura e Arte, possibilitando apenas o trabalho dos conteúdos programáticos de cada componente curricular.

\section{UM RELATO DISCENTE, POR EMILY SABRINA GUEDES PIMENTA}

O projeto IFaz de conta abordou o teatro no IFPR, ramo artístico que ainda não tinha sido explorado no campus Cascavel. O projeto contou com distintos tipos de pessoas: alguns já possuíam um interesse pela área do teatro, outros eram muito tímidos e nunca haviam tido contato com as artes cênicas, nem imaginavam como seria.

Com o início dos ensaios, deparamo-nos com algo completamente diferente do que esperávamos: os jogos teatrais. Quando decidimos participar do projeto, pensamos que nosso papel seria decorar determinado texto e reproduzi-lo através 
da representação. Contudo, nosso primeiro encontro nos mostrou que para fazermos teatro, teríamos que conhecer o teatro.

Nós tivemos aulas sobre a teoria, a fim de entender de forma aprofundada 0 que teríamos que fazer para interpretar qualquer tipo de texto. Estudamos a respeito da fala, expressão corporal e expressão facial: fomos capazes de entender a importância da gestualidade, do caminhar e de como o corpo é capaz de falar. Conhecemos a importância do volume e do tom da fala, com o objetivo de demonstrar os sentimentos de uma determinada personagem interpretada, e relevância da clareza no momento de proferir as falas. Por fim, compreendemos a dimensão da expressão facial quando estamos atuando, já que os mais variados sentimentos da personagem são transmitidos com o olhar, com o sorriso e com as expressões do rosto de quem interpreta. Além de tudo o que já fora mencionado, estudamos a sonografia, a luz, o cenário, o figurino, a maquiagem e o improviso.

Após conhecermos o teatro e sua importância teoricamente/tecnicamente, o levamos para a prática e, por meio dos jogos teatrais, fomos capazes de progredir na interpretação. Nós trabalhamos a voz com expressões vocais, a expressão facial e corporal com jogos que nos faziam dançar e congelar transmitindo um sentimento, a interação, tanto falando sobre as características físicas, quanto através da imitação do outro, o relaxamento, que nos auxiliava nos momentos de tensão durante as apresentações e, por fim, a improvisação que, além de treinar nossa interpretação, estimulava nossa criatividade.

Os jogos teatrais nos auxiliaram não apenas na interpretação de um papel para uma peça, mas na vida cotidiana. Foram valorosos no desenvolvimento da oralidade, pois alguns de nós éramos excessivamente tímidos e tínhamos dificuldades para nos expressar mesmo diante de quem conhecíamos, além do que os jogos teatrais ajudaram a desenvolver a capacidade de falar em público sem que o nervosismo atrapalhasse, tudo era uma grande e séria brincadeira, ambiguidade proposital. Eles nos ajudaram a adquirir hábitos de beber bastante água e aquecer a voz sempre que possível, com a intenção de prevenir uma rouquidão. Enfim, o teatro, por meio dos jogos teatrais, foi de grande valia para que pudéssemos conhecer o outro e o nosso próprio corpo, unido à capacidade de falar muito sem transmitir uma palavra.

Depois de toda a preparação, os integrantes da companhia começaram a ensaiar a peça teatral "Ratimbum Pararatimbum", de Paulo Scaldassy. Trata-se de 
uma peça infantil que frisa a importância das crianças se desligarem um pouco da tecnologia e brincarem com brinquedos reais. Em paralelo, três membros da companhia foram escolhidos para representar o IFaz de conta no Pré-sepin, com a peça teatral curta "As inventariantes", de Walter Piva. Trata-se de um jogo da roleta russa, no qual a esposa e a filha desejam imensamente a morte do esposo/ pai.

Todavia, não contentes com apenas a interpretação, os alunos participantes decidiram fazer uma edição em ambas as peças, trazendo-as mais para a realidade e provocando uma maior reflexão acerca dos temas abordados. Dessa forma, os participantes da companhia tiveram contato com a escrita e com a edição de roteiros, escrevemos e reescrevemos incontáveis vezes.

Com os ensaios feitos, o cenário, o figurino e a sonoplastia ficaram por conta dos próprios participantes que, unindo seus pertences e trabalhando em equipe, criaram uma visão interessante e simples para o público. As apresentações ocorreram e, junto com elas, conhecemos a emoção de estar em um palco interpretando. No momento em que iniciamos as apresentações, descobrimos que deixamos nossas vidas de lado para tomar para nós a vida da personagem que interpretávamos. Mudamos nossos sentidos, modos, personalidade, sentimentos e sonhos a fim de nos tornarmos outra persona e, de forma grandiosa, fomos aplaudidos por isso.

A companhia trouxe para nós resultados além dos esperados para o palco. Tornamo-nos indivíduos com maior facilidade de comunicação, como em discursos públicos, com a capacidade de improvisar, de nos expressar e de controlar nossas emoções. Uns de nós amamos o teatro e descobrimos nele um tratamento para problemas de fala. Outros, para despertar a criatividade. Uns de nós vimos no teatro o mundo que queremos para nossas vidas. Contudo, todos nós vimos o teatro como uma arte necessária para a vida de todo ser humano, pois, além de despertar no público a criticidade e diversão, é capaz de despertar no ator a capacidade de viver a vida de outros, controlar suas emoções, adquirir facilidade na fala, improvisar e, acima de tudo, encontrar-se e conhecer-se como ser humano. 


\section{CONSIDERAÇÕES FINAIS}

O Projeto Ifaz de Conta, quando se constituiu, tinha como iniciativa incluir o teatro de modo prático e efetivo no ambiente escolar. Além de disso, intencionava incluir os indivíduos a partir da linguagem teatral, pois é um instrumento eficaz no despertar da sensibilidade, da comunicabilidade, do conhecimento do outro e do autoconhecimento.

Buscou-se, com a efetivação do projeto, a criação de um espaço no qual os alunos pudessem ter acesso a esta linguagem, oportunizando o desenvolvimento de habilidades que são essencialmente oferecidas por intermédio dela. Nesse ínterim, o acesso desses alunos a esta linguagem artística não se limitou a simples e pura inclusão de apenas um grupo de alunos a esse modo de se fazer arte, mas tentou ampliar a oferta do teatro aos demais indivíduos da comunidade local, indo além da sala de aula, replicando-o por intermédio das apresentações à comunidade, embora as abordagens tenham sido diferentes, de acordo com cada seguimento.

A efetivação do projeto se pautou, inicialmente, na elucidação do teatro como atividade humana importante e indissociável para o desenvolvimento do indivíduo. Houve o ensinamento de conteúdos teóricos e práticos para demonstrar que o teatro também se constitui como uma ciência, sendo uma área do conhecimento tão importante e fundamentada como as outras.

Optou-se, dessa maneira, para o ensino do teatro e a compreensão de sua importância na formação escolar, social e cultural, o uso de instrumentos já familiarizados pelos alunos, como a leitura e a escrita (leitura de textos literários e adaptação de roteiros), ampliando-os a partir da expressão oral e corporal, utilizando-se, essencialmente, da ludopedagogia,

Para uma abordagem lúdica efetiva, recorremos aos ensinamentos de teóricos como Vygostsky, Koudela, Friedmann entre outros, que enfatizam a importância das atividades lúdicas e dos jogos teatrais para a apreensão de habilidades que contribuem com a formação humana, não só para o teatro, mas contribuindo em várias esferas sociais, com no desenvolvimento da criatividade, da auto-expressividade, da sensibilidade interpretativa e das relações interpessoais.

Desse modo, o Ifaz de Conta, tentou trabalhar com diferentes modos metodológicos, enfatizando a inclusão dos alunos participantes independente de sua familiarização prévia com a linguagem do teatro. A brincadeira, por intermédio de 
jogos teatrais e improvisações pôde tornar a atividade teatral, que em vários momentos exige a exposição do indivíduo ao outro, uma forma menos "agressiva" e individual, tornando-se mais coletiva e confortável, especialmente aos indivíduos que tinham vergonha na exposição ao público.

Estas atividades lúdicas e dinâmicas se replicaram durante todo o projeto, criando um ambiente cada vez mais confortável para o amadurecimento das habilidades tão caras para a elaboração do espetáculo. Tais métodos surtiram, em médio prazo, um efeito positivo, desinibindo os alunos e auxiliando em questões que iam além do âmbito artístico, como relatou a aluna Emily, contribuindo, inclusive, para as vivencias cotidianas.

O projeto tornou-se mais produtivo quando percebemos que as metodologias aplicadas conseguiram desenvolver os diferentes integrantes da equipe, possibilitando a montagem de duas peças teatrais, superando as dificuldades e limitações técnicas que enfrentávamos com um grupo de características tão híbridas. Com esse resultado, a criação do espetáculo, o projeto se tornou um agente importante na promoção e valorização da arte teatral, podendo replicar o produto artístico e criar um hábito furtivo, não só para os alunos participantes do projeto, mas também para a comunidade local.

O Ifaz de Conta, nessa perspectiva, pôde se constituir de maneiras distintas; primeiro no desenvolvimento direto dos alunos participantes, ensinando a teoria e a prática de maneira lúdica e interdisciplinar; e posteriormente, na formação da platéia, na elaboração do teatro como um elemento que também pode ser compreendido pela parcela da sociedade que não o produz e que muitas das vezes não tem acesso contínuo a ele, mas que é capaz de consumi-lo e valorizá-lo, identificando-se com as temáticas abordadas e fazendo relações com sua realidade sociocultural.

\section{REFERÊNCIAS}

AMARAL, Ana Maria. Teatro de formas animadas: máscaras, bonecos, objetos. São Paulo: Editora da Universiade de São Paulo, 1996.

BOAL, Augusto. $O$ teatro como arte marcial. Rio de Janeiro, Garamond, 2003. Disponível em $<$ https://books.google.com.br/books?id=DKmogwob0OwC\&printsec=frontcover\&dq=teatr 
o\&hl=pt-BR\&sa=X\&redir_esc $=\mathrm{y} \# \mathrm{v}=$ onepage $\& \mathrm{q}=$ teatro\& $\mathrm{f}=\mathrm{false}>$ Acesso em agosto de 2017.

O arco íris do desejo: o método Boal de teatro e terapia. Rio de Janeiro, Civilização Brasileira, 1996.

BRASIL. Lei n. 9394, de 20 de maio de 1996. Estabelece a lei de diretrizes e bases da educação nacional. Lei de Diretrizes e Bases da Educação-LDB. Brasília, DF, 1996. Disponível em: < http://www.planalto.gov.br/ccivil_03/Leis/L9394.htm>. Acesso em: agosto de 2017.

BRASIL. Parâmetros Curriculares Nacionais: vol 6. Brasília, 2000.

CARTAXO, C. O ensino das artes cênicas na escola fundamental e média. João Pessoa, Editora da UFPB, 2001.

DAVÖ, Solyen. Do palco da escola para o teatro da vida. São Paulo, 2015. Disponível em $<$ https://books.google.com.br/books?id=tK6sCQAAQBAJ\&pg=PA66\&dq=teatro+na+esc ola\&hl=pt-BR\&sa=X\&redir_esc=y\#v=onepage\&q=teatro\%20na\%20escola\&f=false $>$

FRIEDMANN, A. Brincar: crescer e aprender - o resgate do jogo infantil. São Paulo, Moderna, 1996.

KOUDELA, I. D. Jogos Teatrais. São Paulo, Perspectiva, 2012.

LUCKESI, C. C. E. Ludopedagogia, Educação e Ludicidade. Gepel - Grupo de Estudo e Pesquisa em Educação e Ludicidade. Salvador, p. 57, 2000.

PEIXOTO, F. Teatro. São Paulo, Brasiliense, 2012.

ROLIM, A. M.; GUERRA, S. F.; TASSIGN, M. M. Uma leitura de Vygotsky sobre o brincar na aprendizagem e no desenvolvimento infantil. Humanidades, Fortaleza, v. 23, p. 176-180, jul./dez. 2008. ISSN 2.

TAGLIARI, M. Teatro/educação: Ludopedagogia crítica pelo jogo teatral potencializado pelo conflict game com alunos do ensino fundamental de Goiânia-GO. 2015. 204f. Dissertação (Mestrado Interdisciplinar em Performances Culturais). Universidade Federal de Goiás. Goiânia: [s.n.].

VYGOTSKY, L. S. A formação social da mente. 6. ed. São Paulo, Martins Fontes, 1998 